\title{
Low levels of nestmate discrimination despite high genetic differentiation in the invasive pharaoh ant
}

Anna M Schmidt*1, Patrizia d'Ettorre1,2 and Jes S Pedersen ${ }^{1}$

\begin{abstract}
Background: Ants typically distinguish nestmates from non-nestmates based on the perception of colony-specific chemicals, particularly cuticular hydrocarbons present on the surface of the ants' exoskeleton. These recognition cues are believed to play an important role in the formation of vast so-called supercolonies that have been described for some invasive ant species, but general conclusions about the role of these cues are hampered by only few species being studied. Here we use data on cuticular hydrocarbons, aggression and microsatellite genetic markers to investigate the interdependence of chemical recognition cues, genetic distance and nestmate discrimination in the pharaoh ant (Monomorium pharaonis), a widespread pest species, and ask whether introduced populations of this species are genetically differentiated and exhibit intraspecific aggression.
\end{abstract}

Results: Microsatellite analyses of a total of 35 colonies from four continents revealed extremely high levels of genetic differentiation between almost all colonies $\left(F_{\mathrm{ST}}=0.751 \pm 0.006 \mathrm{SE}\right)$ and very low within-colony diversity. This implies that at least 34 and likely hundreds more independent lineages of this ant have spread worldwide. Aggression tests involving workers from 14 different colonies showed only low levels of aggression, even between colonies that were geographically and/or genetically very distant. Chemical analyses of groups of worker ants showed that all colonies had the same cuticular compounds, which varied only quantitatively among colonies. There was a positive correlation between geographical and genetic distance, but no other significant relationships were detected between aggression, chemical profile, genetic distance and geographical distance.

Conclusions: The pharaoh ant has a global invasion history of numerous independent introductions resulting in genetically highly differentiated colonies typically displaying surprisingly low levels of intraspecific aggression, a behaviour that may have evolved in the native range or by lineage selection in the introduced range.

\section{Background}

Unicoloniality, in which individuals from geographically separated nests intermix without aggression, has long been considered a key characteristic of invasive ants [e.g. [1-3]]. Colonies of invasive ant species can become dominant in the invaded habitats and are often termed "supercolonies" due to their sizes and huge potential for growth. Unicolonial species are assumed to have a competitive edge over other ant species, as lack of intraspecific aggression may enable a more effective resource allocation [4-7]. The precise mechanisms enabling the formation of supercolonies are a topic of some discussion $[3,8]$. However, several hypotheses stress the potentially impor-

* Correspondence: amschmidt@bio.ku.dk

${ }^{1}$ Centre for Social Evolution, Department of Biology, University of Copenhagen, Universitetsparken 15, DK-2100 Copenhagen, Denmark Full list of author information is available at the end of the article tant role of diversity of recognition cues and discrimination behaviour, although the hypotheses differ with respect to the role of ecological conditions and whether important traits for supercolony formation developed before or after the ants were introduced outside their native range and became invasive pests [9-11].

Cuticular hydrocarbons (CHCs) play a central role in ant communication and nestmate discrimination $[12,13]$. These lipids lower the risk of desiccation, can reflect environmental as well as genetic variation $[13,14]$, and likely have evolved to function as recognisable labels enabling discrimination of nestmates from non-nestmates. Several studies have established a role for $\mathrm{CHCs}$ in intraspecific discrimination in ants [e.g. [15-17]], and differences in cuticular hydrocarbon profiles can often be correlated with aggression probabilities, as antagonism is 
expected to be expressed when odour dissimilarity exceeds a given threshold [12,18-20].

The pharaoh ant (Monomorium pharaonis) is a ubiquitous invasive ant species [21]. The species is mainly found in buildings and as such a common household pest. Like other invasive ant species it has a high potential for spread $[2,22,23]$ and is polygynous, i.e. several queens reproduce in a colony. Polygyny is hypothesized to lead to lower levels of nestmate recognition relative to monogynous (single queen) species, perhaps because of the expected higher levels of genetic diversity within a colony containing multiple reproducing individuals [24]. Low levels of intraspecific aggression, if aggression depends on nestmate recognition, may therefore have facilitated the spread of pharaoh ants $[2,21,25]$.

Here we test the hypothesis that pharaoh ants, like several other well-known invasive ant species, exhibit low levels of intraspecific aggression, and we investigate the possible role of cuticular hydrocarbons in discrimination behaviour by measuring aggression within and between laboratory strains and free-living colonies to (1) assess whether discrimination behaviour is common and (2) test whether it is primarily genetically or environmentally determined. In order to do so, we examined the extent to which the discrimination behaviour is correlated with the cuticular hydrocarbon profiles of the ants and the level of genetic differentiation between them. Finally, we studied discrimination abilities of $M$. pharaonis towards another tramp ant species, $M$. destructor, to (1) investigate whether aggression against other ant species occurred and (2) compare the chemical profiles of the two species to obtain chemotaxonomic evidence for the species identifications, (cuticular hydrocarbons are usually species specific [see e.g. [13,14]]).

We found very high levels of genetic differentiation between the different colonies and discrimination behaviour to be uncommon at first, although aggression increased with time spent in the laboratory. We found no clear correlates of inter-colonial aggression. Interspecific aggression was very high, and the two species studied had clearly distinct chemical profiles.

\section{Methods}

\section{Study material}

A total of 35 colony samples of $M$. pharaonis were obtained in 2004; 14 of these were live samples, either from laboratory stocks $(n=6)$, or from field collection (primarily in or on buildings, $n=8$; Table 1 ). Sampling was opportunistic to represent as many different localities around the world as possible. The most extensive sampling was performed in Ghana in October 2004 to obtain colonies or colony samples from the tropics, where the species is generally more common [26]. All laboratory colonies had been reared in captivity for several years.
Three samples of $M$. destructor were also collected in the field in Ghana in October 2004 (at Cape coast, Nsawam and Winniba) to be used for interspecific behavioural experiments and chemical analyses. M. destructor is a widespread tramp ant species, very similar to $M$. pharaonis in habitat usage as well as social structure, and the two species would typically be found at the same type of localities although not co-occurring [[27], AMS personal observation].

Worker samples for genetic studies were stored in 96\% $\mathrm{EtOH}$ until analysed. Live colonies (including queens and brood) and colony samples consisting of workers to be used for behavioural and chemical studies were kept in the laboratory under uniform conditions of $25^{\circ} \mathrm{C}, 12 / 12$ hour light/dark cycle and provided with water ad libitum and a diet of boiled egg yolk, cooked liver, honey, almonds and dead insects twice a week. Five viable colonies were kept for more than one year so that two independent series of behavioural and chemical tests (2004 and 2005) could be done. Since the workers' lifespan is 910 weeks on average [28] and unlikely to exceed four months (AMS, personal observation), and even the queens have rarely been observed to live for more than one year, repeating experiments after one year ensured that individuals tested in the second round would likely not carry any cues derived from their previous environments. Of the five colonies tested again in 2005, four were originally laboratory colonies and one was a field colony, collected in Ghana in 2004 (cf. Table 1).

\section{Genetic analyses}

The genetic variation and differentiation of the colonies was examined based on four microsatellite loci for which primers were developed for M. pharaonis (Table 2). DNA was extracted from 30 workers from each colony (except 6 workers from U19) by each specimen being crushed in $200 \mu \mathrm{l}$ 5\% Chelex solution. The primers were run in separate PCR reactions in $20 \mu \mathrm{l}$ reaction volumes with $1 \mu \mathrm{l}$ extract as template, reaction buffer, $25 \mathrm{mM} \mathrm{MgCl}_{2}, 0.5$ mM GATC, $10 \mu \mathrm{M}$ forward and reverse primers and 0.1 $\mu \mathrm{l}$ Taq gold polymerase. The PCR reaction conditions consisted of an initial denaturing step of $95^{\circ} \mathrm{C}$ for $10 \mathrm{~min}$, followed by 27 cycles of $95^{\circ} \mathrm{C}$ for $30 \mathrm{~s}, 60^{\circ} \mathrm{C}$ for $30 \mathrm{~s}$, and $72^{\circ} \mathrm{C}$ for $30 \mathrm{~s}$, and finally an extension step at $72^{\circ} \mathrm{C}$ for $1 \mathrm{~h}$. The PCR products were run on $2 \%$ ethidium bromide agarose gels, and subsequently run on $5 \%$ polyacrylamide gels using an ABI PRISM 377 DNA automated sequencer with Rox500 as internal standard. The four loci can be multiplexed on the ABI. GENESCAN 3.1 and GENOTYPER 3.1 were used to score the alleles.

\section{Cuticular hydrocarbon analyses}

Groups of 5 workers per colony were frozen at $-20^{\circ} \mathrm{C}$ after which surface chemicals were extracted by washing in 20 
Table 1: Samples of Monomorium pharaonis.

\begin{tabular}{|c|c|c|c|c|c|c|c|}
\hline Colony ID & Locality & Sample type & $P$ & $\boldsymbol{k}^{\prime}$ & $H_{\text {exp }}$ & $M$ & $\begin{array}{l}\text { Intraspecific } \\
\text { tests } 2004\end{array}$ \\
\hline Gh1 & Legon, Ghana ${ }^{1}$ & Field & 1 & 1.45 & 0.141 & -- & $52(47 ; 5)$ \\
\hline Gh4 & Fete, Ghana ${ }^{1}$ & Field & 3 & 1.74 & 0.227 & $0.35^{*}$ & $55(53 ; 5)$ \\
\hline Gh6 & Asuansi, Ghana & Field & 3 & 1.64 & 0.199 & $0.52^{*}$ & \\
\hline Gh7 & Biriwa, Ghana1 & Field & 3 & 2.27 & 0.390 & $0.44^{*}$ & $37(31 ; 2)$ \\
\hline Gh8 & Koforidua, Ghana ${ }^{1}$ & Field & 3 & 2.64 & 0.374 & $0.47^{*}$ & $47(44 ; 5)$ \\
\hline Gh9 & CRIG, Ghana ${ }^{1}$ & Field & 2 & 1.34 & 0.144 & 0.75 & $46(42 ; 5)$ \\
\hline Gh10 & Legon, Ghana' ${ }^{1}$ & Field & 2 & 1.27 & 0.073 & 1 & $45(39 ; 5)$ \\
\hline Gh11 & Iturie, Ghana ${ }^{1}$ & Field & 0 & 1 & 0 & -- & $60(59 ; 5)$ \\
\hline Gh12 & CRIG, Ghana & Field & 1 & 1.27 & 0.072 & 1 & \\
\hline Gh13 & Pokwasi, Ghana & Field & 3 & 2.01 & 0.362 & 0.70 & \\
\hline Gh14 & Aburi, Ghana & Field & 1 & 1.15 & 0.032 & $0.40^{*}$ & \\
\hline Gh15 & CRIG, Ghana & Field & 3 & 1.59 & 0.246 & 0.76 & \\
\hline Gh16 & Tafo, Ghana & Field & 3 & 2.14 & 0.315 & $0.51^{*}$ & \\
\hline Gh17 & Tafo, Ghana & Field & 2 & 1.81 & 0.248 & $0.31^{*}$ & \\
\hline $\mathbf{T}$ & Tingbjerg, Denmark & Field & 0 & 1 & 0 & -- & \\
\hline 14 & Copenhagen, Denmark ${ }^{1}$ & Field & 2 & 1.27 & 0.073 & 0.67 & $48(47 ; 5)$ \\
\hline D & Bonn, Germany ${ }^{1}$ & Field & 1 & 1.05 & 0.008 & 1 & $51(49 ; 5)$ \\
\hline $\mathbf{z}$ & Zürich, Switzerland & Field & 1 & 1.19 & 0.046 & 0.67 & \\
\hline TW & Taiwan & Laboratory & 1 & 1.25 & 0.124 & $0.03^{*}$ & \\
\hline C & Cameroon & Field & 3 & 2.12 & 0.404 & $0.33^{*}$ & \\
\hline U1 & Florida, USA ${ }^{1}$ & Laboratory & 1 & 1.05 & 0.008 & $0.29^{*}$ & $51(51 ; 5)$ \\
\hline U2 & Texas, USA ${ }^{1}$ & Laboratory & 3 & 1.94 & 0.356 & $0.46^{*}$ & $50(47 ; 5)$ \\
\hline U3 & Florida, USA ${ }^{1}$ & Laboratory & 3 & 2.03 & 0.318 & $0.51^{*}$ & $50(49 ; 5)$ \\
\hline U4 & Penang, Malaysia ${ }^{1}$ & Laboratory & 1 & 1.05 & 0.008 & 1 & $61(57 ; 4)$ \\
\hline U5 & London, UK'1 & Laboratory & 3 & 1.74 & 0.332 & 0.66 & $51(48 ; 5)$ \\
\hline U6 & Debrecen, Hungary & Laboratory & 0 & 1 & 0 & -- & \\
\hline U7 & Warsaw, Poland & Laboratory & 1 & 1.25 & 0.122 & $0.33^{*}$ & \\
\hline U8 & Okinawa, Japan & Laboratory & 2 & 1.35 & 0.144 & $0.33^{*}$ & \\
\hline U9 & Kyoto, Japan & Laboratory & 2 & 1.28 & 0.079 & 1 & \\
\hline U10 & Moscow, Russia & Field & 1 & 1.05 & 0.008 & 1 & \\
\hline U11 & Texas, USA & Field & 2 & 1.49 & 0.201 & 0.83 & \\
\hline U17 & Lambto, Ivory Coast & Field & 2 & 1.54 & 0.211 & 0.83 & \\
\hline U18 & BCl, Panama & Field & 1 & 1.32 & 0.076 & 0.50 & \\
\hline U19 & Gamboa, Panama & Field & 0 & 1 & 0 & -- & \\
\hline U20 & Montreal, Canada & Field & 0 & 1 & 0 & -- & \\
\hline
\end{tabular}

The colony ID is the abbreviations used in further analyses and figures. The total number of polymorphic loci was four; $P$ is the number of polymorphic loci for a given colony. $k$ ' is the average allelic richness adjusted to sample size of six. $H_{\text {exp }}$ is the expected average heterozygosity for each colony. ${ }^{*}$ indicate statistically significant $M$ values $(P<0.05$; see Methods for details). The colony samples consisted of either workers in alcohol, live workers only, or colonies of varying sizes containing queen(-s) and brood in addition to workers. 'Field' samples were collected in the field October 2004 and 'Laboratory' samples had been kept in other laboratories as well as in Copenhagen. The number of intraspecific tests is the total number of intraspecific, inter-colonial tests conducted involving each of the populations in 2004. The number of inter-colonial tests where interactions occurred are given first in the parentheses, the number of within-colony control tests are given second in the parentheses. In 2005 colonies U1, U2, U3, U4 and Gh4 were used for behavioural tests and chemical analyses, 6 tests were made for each possible intraspecific combination of colonies as well as for the within-colony controls. ${ }^{1}$ indicate sample used for correlation analyses including behavioural experiments and chemical analyses. 
Table 2: Microsatellite loci developed and analysed in this study

\begin{tabular}{|c|c|c|c|c|c|}
\hline Locus & Primer sequences (5'-3') & Repeat motif & GenBank accession no. & No. of alleles & Size range (bp) \\
\hline \multirow[t]{2}{*}{ Mp1 } & f: GCCAATGGTTTAATCCCTCA & $(\mathrm{AG})_{3} \mathrm{AA}(\mathrm{AG})_{23}$ & $\underline{\mathrm{HM} 587312}$ & 15 & $192-279$ \\
\hline & r: TCATACTGCGTGTGCCTITC & & & & \\
\hline \multirow[t]{2}{*}{ Mp3 } & f: ACAAGGTAAGTCGCCACCAT & $(\mathrm{GT})_{20}$ & $\underline{\text { HM587313 }}$ & 9 & $127-147$ \\
\hline & r: TCGTGATAATTCGCGATGAA & & & & \\
\hline \multirow[t]{2}{*}{ Mp12 } & f: TGGCCAAAAGTATCCAGGAG & $(\mathrm{AC})_{8}$ & $\underline{\mathrm{HM} 587314}$ & 2 & $130-132$ \\
\hline & r: TCGTCGAAAGTATCGAAGTAAAC & & & & \\
\hline \multirow[t]{2}{*}{ Mp13 } & f: CCCATTGAGATTGCGGCAT & $(\mathrm{AC})_{10}(\mathrm{GC})_{8} \mathrm{ACA}(\mathrm{AC})_{10}$ & $\underline{\mathrm{HM} 587315}$ & 9 & $281-298$ \\
\hline & r: GCACAGGCACGTAACGATT & & & & \\
\hline
\end{tabular}

Data on allele number and size range are for the total sample of 35 Monomorium pharaonis colonies analysed ( $n=1026$ individuals).

$\mu \mathrm{l}$ pentane for $10 \mathrm{~min}$. Three $\mu \mathrm{l}$ of this solution was injected into an Agilent Technologies 6890N Gas Chromatograph (GC) equipped with a capillary column (HP5MS $30 \mathrm{~m} \times 250 \mu \mathrm{l} \times 0.25 \mu \mathrm{m})$. The injector was a split-splitless type with helium carrying gas at $1 \mathrm{ml} / \mathrm{min}$. The initial temperature was $70^{\circ} \mathrm{C}$, and was increased at $20^{\circ} \mathrm{C} / \mathrm{min}$ to $280^{\circ} \mathrm{C}$, then to $310^{\circ} \mathrm{C}$ at $2^{\circ} \mathrm{C} / \mathrm{min}$, and held for $5 \mathrm{~min}$. The GC was coupled with a 5375 Agilent Technologies Mass Spectrometer, using $70 \mathrm{eV}$ electron impact ionization. Compounds were identified on the basis of their mass spectra, and comparison with standards and published spectra. One sample was run for each colony. A single, concentrated reference of 25 pooled individuals (colony U1 used) was analysed to ascertain the identity of the peaks used in the subsequent analyses.

\section{Behavioural experiments}

Standardized aggression tests were performed where dyadic encounters were continuously observed over 10 min following Giraud et al. [4] with the modification that we allowed the ants to habituate separately for $1 \mathrm{~min}$ within the arena before the start of the observation period. All interactions were scored in easily distinguishable categories on a scale from 0 to 5 : levels 0 (no response) and 1 (antennation) were considered neutral, non-aggressive behaviours, and levels 2 (escape), 3 (gaster raising), 4 (biting), and 5 (fighting, which involved prolonged biting, often ensuing in one ant biting onto the other for the remainder of the observation period) were considered antagonistic. Within 6 weeks from field collection in 2004 a mean of 3.9 tests (median $=5$, range 1-6) were carried out for each intraspecific $M$. pharaonis colony pair as well as for the controls (i.e. within-colony controls). 5 tests were conducted for each interspecific combination of $M$. pharaonis vs. $M$. destructor (except Gh7 with one test in two of the combinations) and for the $M$. destructor within-colony control tests, to obtain a matrix of 635 tests in total. In 2005 a sub-sample of 5 of the M. pharaonis colonies was tested, with 6 tests for each possible intraspecific combination of colonies as well as for the within-colony controls, resulting in 90 intraspecific tests in total. The tests were not done blind as regards the colony origin of the ants, but the interaction categories were clearly distinguishable, thus preventing any subjectivity in the interpretation of the behaviour. Moreover, the experimenter had no prior knowledge of the genetics or chemical profiles of the colonies. No ants were used for more than one test to avoid any possible effects of familiarization.

\section{Statistical analyses}

The genetic differentiation $\left(F_{\mathrm{ST}}\right)$ between the colonies as well as measures of allelic richness $\left(k^{\prime}\right)$ and inbreeding at the colony level $\left(F_{\text {IS }}\right)$ were calculated using FSTAT 2.9.3.2 [29] with significance testing based on 15,000 randomisations. Standard errors were estimated by jack-knifing over colonies. As the value of $F_{\mathrm{ST}}$ is affected by the allelic diversity at the marker loci applied, we further calculated the standardised $F_{\mathrm{ST}}^{\prime}[30]$ and the estimator $D_{\text {est }}$ [31] as alternative quantifications of the genetic differentiation, making comparisons with studies based on other marker loci possible [32].

The program M_RATIO [33], was applied to test for signs of population bottlenecks as $M$ is the ratio of allele number to range in allele sizes $(M=k / r)$, and a significant reduction in $M$ relative to the expected distribution is interpreted as an indication of a recent reduction in population size. The estimates of $M$ were based on simulation of 10,000 replicates for the polymorphic loci. We applied the non-spatial genetic mixture analysis implemented in BAPS 5.3 [34] to cluster colonies that are likely to be genetically similar e.g. from having a common population history or representing the same supercolony $[35,36]$. The maximum number of genetically divergent groups $(K)$ was set to the number of colonies included in the data 
set, and each analysis was repeated 10 times to ensure consistency of results between different runs. The genetically divergent groups of colonies identified this way are interpreted as colony lineages. Based on the observed number of lineages in our sample we estimated the total number of such lineages in the world by the Chao1 estimator of Chao [37] using the program SPADE [38]. Furthermore, a principal component analysis (PCA) of the microsatellite allele frequency data was performed in PCAGEN 1.3.1 [39], as an exploratory technique to visualise colony or population associations possibly reflecting the phylogeographic history of the species.

For the data on chemical profiles STATISTICA 7 (StatSoft) was used to perform PCA on peak areas, after logratio transformation according to Aitchison [40]. In addition, principal components combined explaining a minimum of $95 \%$ of the variation were found in JMP.IN 5.1 and subsequently used for calculating the inter-sample chemical (Euclidian) distances as a measure of their relative differences. Cluster analyses were performed based on the cuticular hydrocarbon data, see additional file 1.

Mantel tests for possible correlations between the chemical and behavioural, genetic as well as geographical distances were performed in FSTAT [29], all based on 10,000 permutations. The results of the subset of colonies that were studied in both 2004 and 2005 were compared with MANOVA. The behavioural data were analysed using Kruskal-Wallis test with Dunn's post-hoc test and Mann-Whitney $U$-test for the 2004 and 2005 data respectively; Fisher's exact test was applied to compare the overall occurrence of aggression between the two years.

\section{Results}

\section{Genetic diversity and differentiation}

Table 2 gives information on the four microsatellite markers that were developed for this study. At one locus $(\mathrm{Mp} 12)$ only two alleles were found, and all colonies except one (TW) were monomorphic for one of these alleles, while TW was monomorphic for the other. The genetic diversity within colonies was generally very low, as over $2 / 3$ of the colonies only had two polymorphic loci, and five of these colonies were monomorphic at all four loci (Table 1). The allelic richness $\left(k^{\prime}\right)$ was $1.47 \pm 0.07 \mathrm{SE}$, the expected heterozygosity $\left(H_{\text {exp }}\right)$ was $0.153 \pm 0.023 \mathrm{SE}$ on average across colonies and, as expected, these measures of the genetic diversity were highly correlated (Spearman $r=0.977 ; P<0.0001$ ). The calculations from the M_RATIO program indicated that 14 of the colonies had likely gone through a reduction in the effective number of reproducing individuals (Table 1 ).

There were no signs of deviation from random mating within the colony samples $\left(F_{\mathrm{IS}}=-0.021 \pm 0.005 \mathrm{SE} ; P=\right.$ 0.82 ), confirming that each colony formed its own breeding population as seen in other invasive ant species (e.g.
[35]). We consistently found very high and statistically significant values of interpopulation genetic differentiation (mean $F_{\mathrm{ST}}=0.751 \pm 0.006 \mathrm{SE} ; P<0.0001$; corresponding to $F_{\mathrm{ST}}^{\prime}=0.891$ and $D_{\text {est }}=0.561$; see also additional file 2 for estimates of pairwise $\left.F_{\mathrm{ST}}\right)$. Only two colonies (U1 from Florida and U19 from Panama) were grouped as genetically similar by the BAPS analysis, as also reflected in the PCA plot (Fig. 1), and this result ( $K=$ 34) had strong support by a posterior probability $P=$ 1.000 in all 10 runs. Consequently, the group of these two colonies and the 33 remaining colonies were all significantly genetically divergent, indicating that there were 34 independent lineages represented in our sample. Extrapolating this finding using the Chao estimator implies that the total number of such lineages of pharaoh ants in the world should be counted in hundreds, maybe even thousands $\left(S_{\text {Chao1 }}=579 ; 140-300595 \%\right.$ C.I. $)$.

\section{Cuticular hydrocarbon analyses}

The cuticular profile of $M$. pharaonis was characterized by 18 different hydrocarbons, which were a mix of unbranched, mono- and di-methyl-branched alkanes with 25 to 33 carbons and unsaturated hydrocarbons (Fig. 2a). As these hydrocarbons were invariably present, our analysis focused on quantitative differences among $M$. pharaonis colonies. For the 2004 and 2005 data a combined PCA extracted 5 principal components with eigenvalues larger than 1 (eigenvalues and percent variance explained by each of the 5 components: $5.83,32 \%$; 4.53 , $25 \% ; 2.22,12 \% ; 1.52,8 \% ; 1.10,6 \%)$. PCA of all cuticular profiles did not provide clear groupings in either year (Fig. 3), and there were no significant differences in intercolonial chemical distances between the years (MANOVA on first four principal components, $F_{3,2}=$ $0.57 ; P=0.68)$, indicating that laboratory rearing had not lead to convergence of the cuticular profiles. From Fig. 3 there seem to be changes between years, but these are not consistently in any direction, although our sample size of five colonies is too small to test this statistically or to test directly for significant colony-specific changes between years.

Ten hydrocarbons accounted for most intercolony variation (i.e. factor loadings $>0.7$ ) and were a mix of different types, branched as well as unbranched (see legend of Fig. 2a). For the 2004 data there was no significant correlation between chemical distances and level of aggression across colonies (Mantel test, $n=14, r=0.047 ; P=0.65$; Fig. 4). For further illustration of the seeming lack of geographical clustering based on the chemical data see Ward tree based on hierarchical cluster analysis in additional file 1 .

When compared with $M$. destructor, the $M$. pharaonis chemical profiles were clearly qualitatively different: $M$. 


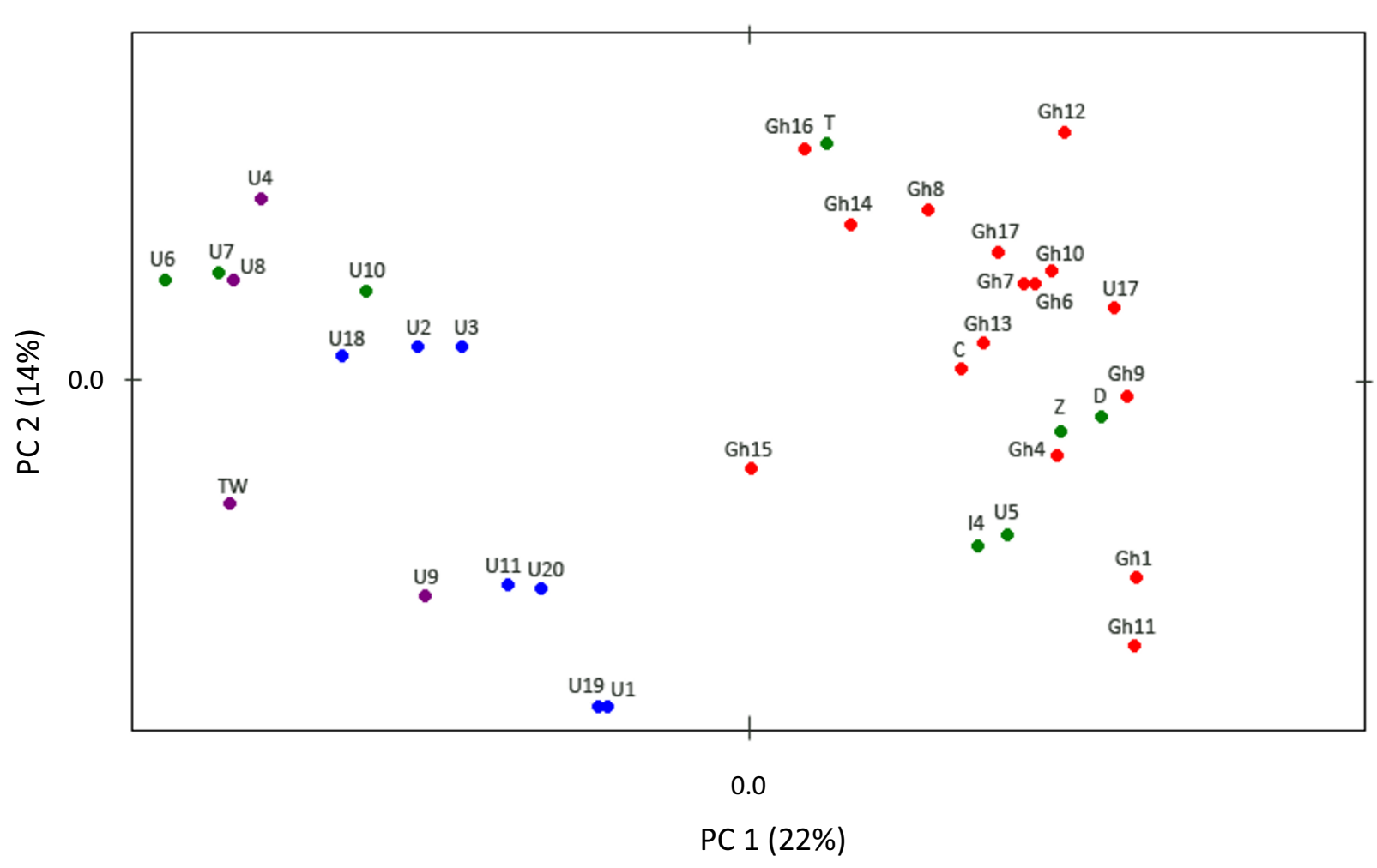

Figure 1 Principal Component Analysis of microsatellite allele frequencies of Monomorium pharaonis colonies. Colour coding is by continent; red: Africa, green: Europe, blue: America, purple: Asia. Colony labels are as in Table 1. The explained variances are given in parentheses.

destructor consisted of 12 hydrocarbons of which only four were also found in M. pharaonis (Fig. 2).

\section{Aggression assays}

In 45 behavioural tests no interactions between the ants were observed, leaving 590 tests for further analyses. Aggression occurred in 23\% (21 out of 91 combinations) of the intraspecific colony pairs obtained in 2004. The average aggression level was $0.99 \pm 0.05$ SD for 14 withincolony control pairs (median $=1$, interquartile range $=0$ ), $1.37 \pm 0.82$ for 91 intraspecific pairs (median $=1$, interquartile range $=0.29$ ), and $3.68 \pm 0.98$ for 42 interspecific pairs $($ median $=3.8$, interquartile range $=1.55)$. There was a significant overall difference (Kruskal-Wallis test, $n$ = 147, $H=85 ; P<0.0001)$, the difference between intraand interspecific aggression also being significant (Dunn's post-hoc test, $n=2$; both $P<0.001$ ), but no significant difference was found between intraspecific and within-colony (control) aggression (Dunn's post-hoc test, $n=2 ; P>0.05$ ), reflecting a generally rare occurrence of intraspecific aggression. The level of aggression between different colonies of $M$. pharaonis did not depend on the presence of queens (Kruskal-Wallis test on queenrightqueenright, queenright-queenless and queenless-queenless colony pairs, $n=91, H=2.96 ; P=0.23$ ). The second series showed higher overall occurrence of intraspecific aggression after one year: whereas aggression was observed in only 1 of the 10 colony combinations in 2004, it was observed in 7 of the 10 combinations in 2005 (Fisher's exact test; $P=0.02$ ) and there was a significant difference between intraspecific and within-colony (control) aggression in 2005 (Mann-Whitney $U$-test, $n=15, U$ $=5 ; P=0.019)$.

\section{Correlation analyses}

The Mantel tests for association of geographical, genetic, chemical, and behavioural distances between colonies ( $n$ $=14$ ) only showed a significant positive correlation for the combination of genetic and geographical distance (Fig.4; $r=0.30, P=0.005$; see Table 1 for colony IDs). Tests for correlation between genetic and geographical distances were also performed for the entire sample of 35 M. pharaonis colonies, as well as for the sub-set from Ghana. The correlation between genetic and geographical distance was also significant for the 35 colonies $(r=$ $0.25, P=0.0001)$. This indicates that there might be genetic isolation by distance between colonies at the global scale. However, the same correlation was not found when the sub-set of colonies from Ghana was analysed separately ( $n=14, r=0.06 ; P=0.57)$. Thus this apparent isolation by distance appears to be a product of generally very high levels of genetic differentiation 


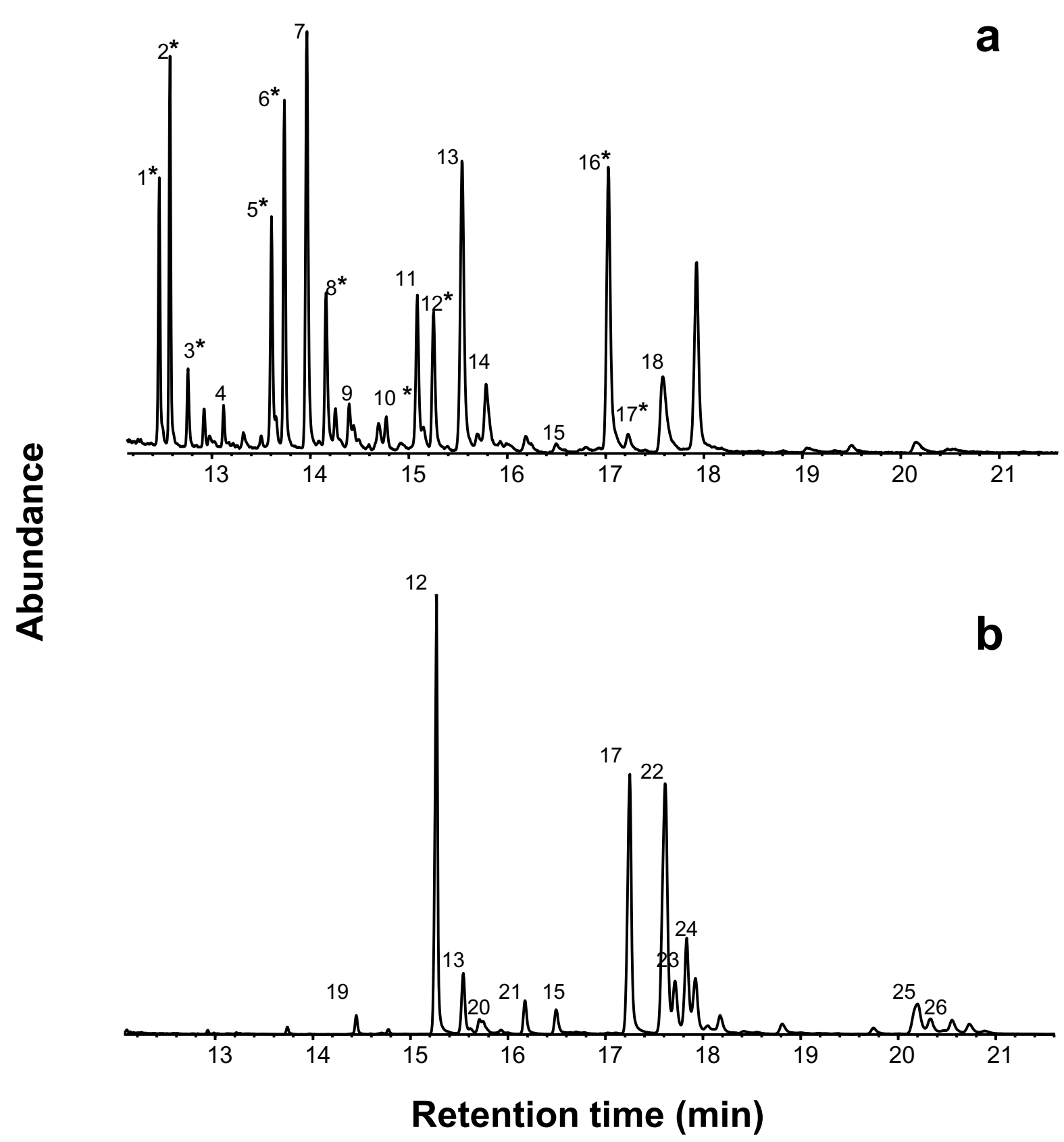

Figure 2 Cuticular hydrocarbon profiles of Monomorium pharaonis (a) and $\boldsymbol{M}$. destructor (b). The numbers on the peaks mark the identified hydrocarbons: (1*) C25:1; (2*) C25; (3*) 9-,11-,13-MeC25; (4) C26; (5*) C27:1; (6*) C27; (7) 9-,11-,13-MeC27; (8*) 11,15-diMeC27; (9) 3-MeC27; (10*) 3,11diMeC27; (11) C29:1; (12*) C29; (13) 11-,13-,15-MeC29; (14) 11,15-diMeC29; (15) 3,11-diMeC29; (16*) C31:1; (17*) C31; (18) 11-,13-,15-MeC31; (19) C28; (20) 5-MeC29; (21) C30; (22) 11-,13-MeC31; (23) 7-MeC31; (24) 5-MeC31; (25) 11-,13-MeC33; (26) 7-MeC33. The numbers with an asterisk denote the hydrocarbons that explain most of the variation in the overall principal component analysis, i.e. numerical value of factor loadings $>0.7$. Factor loadings for these compounds were: (1) -0.736 ; (2) -0.835 ; (3) -0.867 ; (5) -0.745 ; (6) -0.885 ; (8) -0.768 ; (10) 0.797 ; (12) -0.751 ; (16) 0.902 ; (17) -0.841 .

between the colonies, combined with slightly lower levels of differentiation found among the African samples, which, due to their high representation (16 of 35 colonies), skew the distribution in the shorter distance end of the geographical scale.

\section{Discussion}

The very high genetic differentiation between almost all colonies studied suggests that pharaoh ants have made their way to at least four different continents through numerous human-mediated introductions resulting in at 


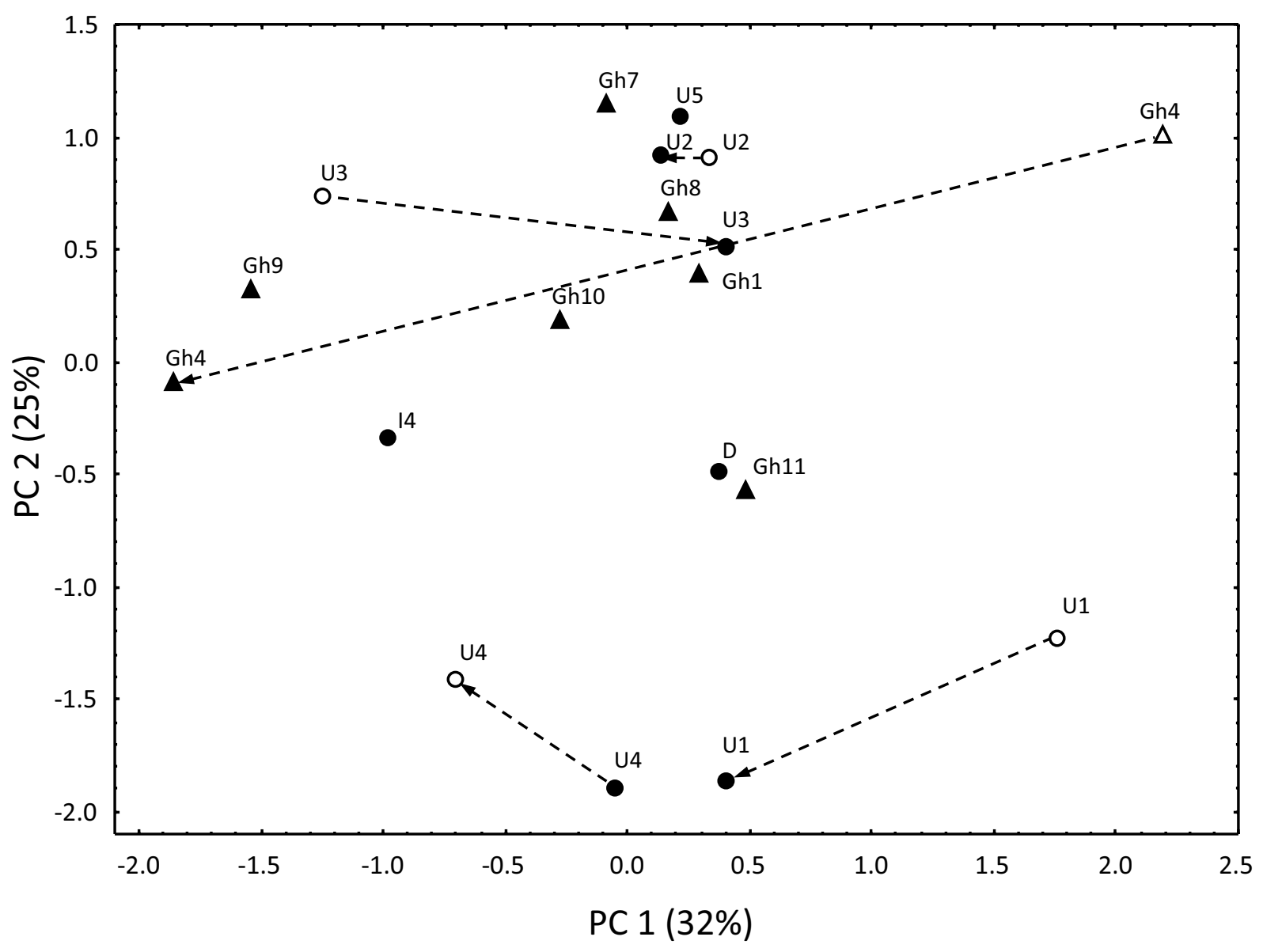

Figure 3 Principal Component Analysis of cuticular hydrocarbons of Monomorium pharaonis colonies. Filled and open symbols indicate colonies analysed in $2004(n=14)$ and $2005(n=5)$, respectively. Colonies from Ghana are shown by triangles, whereas the rest are shown by circles. Dashed lines are drawn between the symbols representing colonies analysed in 2004 and 2005. Colony labels are as in Table 1. The explained variances are given in parentheses.

least 34 and likely hundreds more independent lineages. Colonies appear to have frequently gone through genetic bottlenecks in the introduction process, resulting in possibly isolated colonies with low genetic diversity and extremely high intercolonial differentiation. In fact, to our knowledge, the $F_{\mathrm{ST}}$ value found (0.751) is the largest estimate for genetic differentiation at nuclear loci reported for any non-selfing sexually-reproducing organism. The extreme genetic divergence among lineages is not a statistical artefact of analysing markers of limited allelic diversity, as also the unbiased estimators $F_{\mathrm{ST}}^{\prime}$ and $D_{\text {est }}$ are exceeded by only one similar species among the studies reviewed by Heller and Siegismund [32]. Hence, the pattern of dispersal and organisation in independent supercolonies closely resembles that of other invasive ant species like the Argentine ant (Linepithema humile), $F_{\mathrm{ST}}=$ 0.419; [36] and the invasive garden ant (Lasius neglectus), $F_{\mathrm{ST}}=0.334 ;[41]$, but is characterised by an even larger degree of isolation, likely reflecting a longer invasion history.

We successfully identified 26 cuticular hydrocarbons from the profiles of $M$. pharaonis and $M$. destructor and found only quantitative variation between $M$. pharaonis colonies but clear qualitative differences between the two species (Fig. 2). Although there were extremely high levels of genetic differentiation between the $M$. pharaonis colonies, which led us to speculate whether several cryptic species might be involved, the cuticular data provide chemical evidence that this is not the case. The PCA of the cuticular profiles (Fig. 3) did not disclose any geographical or other groupings among the apparently chemically very similar $M$. pharaonis colonies investigated. Previous studies on the little fire ant (Wasmannia auropunctata) and the Argentine ant (Li. humile) have shown quantitative as well as qualitative differences in chemical profiles between native as well as introduced 


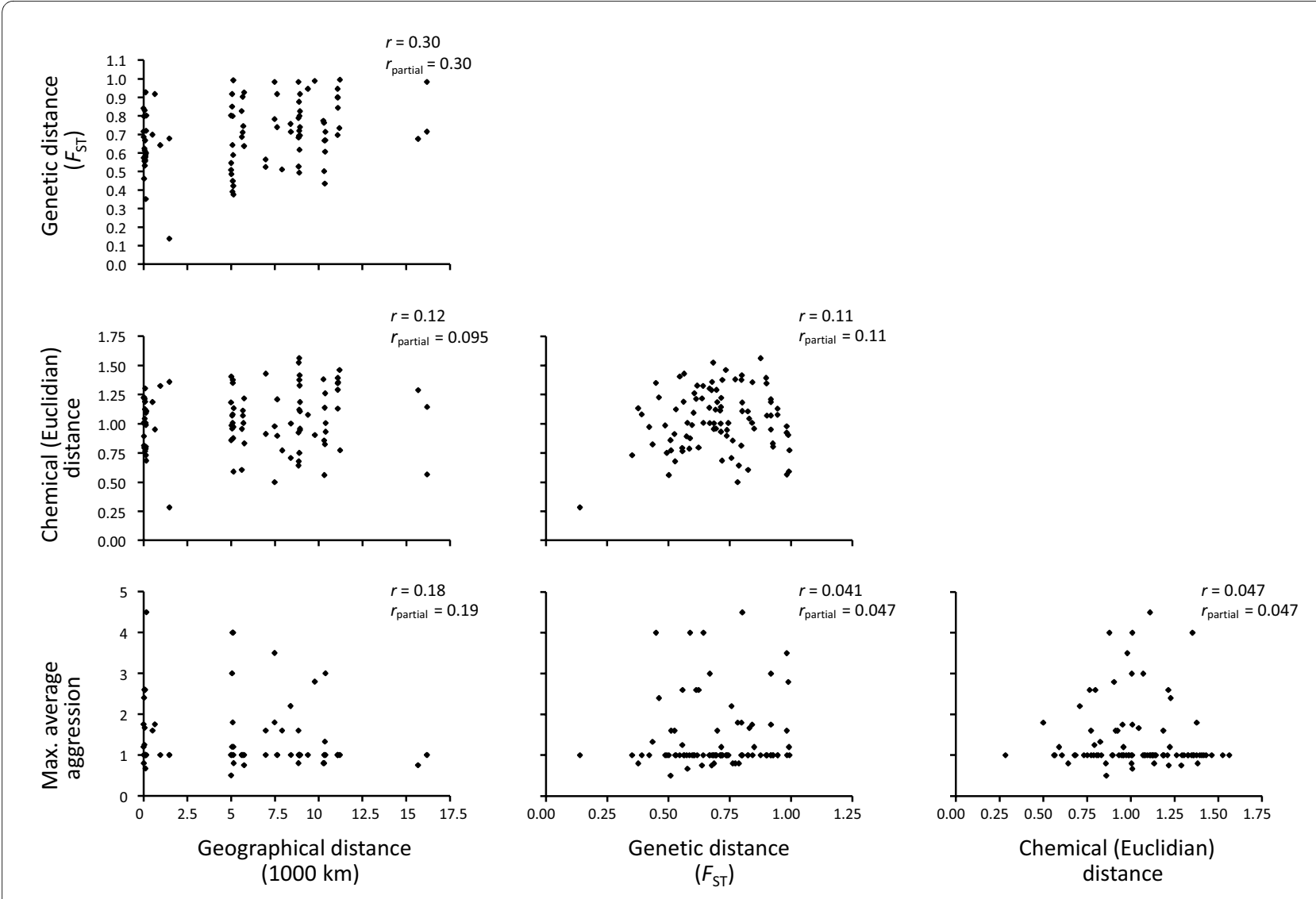

Figure 4 Association of genetic, chemical, behavioural, and geographical distances between colonies of Monomorium pharaonis. Correlation coefficients as well as partial correlation coefficients are given for each plot. Mantel tests yielded insignificant correlations $(P>0.09)$, except for genetic vs. geographical distance $(P=0.005)$.

colonies, with introduced colonies generally having fewer compounds in their profiles [42,43]. These findings indicate that $\mathrm{CHC}$ analyses could potentially be an indirect way of discerning between ants from the native and introduced ranges. However, in our sample all pharaoh ants analysed were chemically qualitatively similar, and had relatively few compounds in their profiles relative to other ant species. This indicates that they are either all from introduced colonies, or that the pattern found in $W$. auropunctata and $\mathrm{Li}$. humile does not apply to this species.

Recent investigations suggest that double-bonded and methylated hydrocarbons may be more informative for nestmate discrimination than other hydrocarbons and that a combination of different classes of hydrocarbons may be necessary for efficient discrimination [17,44-47]. The presence of several methylated hydrocarbons in $M$. pharaonis cuticular profiles therefore indicates that information for nestmate recognition is potentially available.

For another invasive ant species, the Argentine ant, Suarez et al. [48] found a correlation between cuticular chemistry and behaviour even after a year of laboratory rearing, suggesting that nestmate discrimination is a direct function of chemical distance. Likewise, Liang and Silverman [16] and Liang et al., [49] found strong correlational evidence for the importance of environmentally derived hydrocarbon cues in the discrimination behaviour of Argentine ants. The lack of correlation found in our study indicates that there is no similarly simple role of cuticular hydrocarbons in $M$. pharaonis. Interestingly, between-colony aggression had increased after one year of laboratory rearing, the precise mechanism of this, however, is yet to be studied. Like other invasive ants $[3,6]$, M. pharaonis was less aggressive against conspecifics than would be expected based merely on the large geographical distances. For example, there is $>8000 \mathrm{~km}$ between the completely non-aggressive colonies Gh1 and $\mathrm{U} 1$, which are highly genetically distinct $\left(F_{\mathrm{ST}}=0.824\right.$; Bonferroni corrected $P<0.05)$. Although queenless workers are often found to be less aggressive than queenright workers [50], this is not the case for many species including two other invasive ant species, the Argentine ant and the fire ant $[51,52])$, giving us good reason to assume that this would also not be the case for pharaoh 
ants. As our results show no difference in the average level of aggression in interactions involving queenright and/or queenless colonies, we believe that using workers from queenless colonies has not affected our results.

The absence of aggression between distantly related colonies is remarkable and may be a characteristic of the pharaoh ant as an invasive species. As has been suggested for La. neglectus [11] and La. austriacus [53], a reduced diversity of recognition cues or a general abandoning of aggression towards conspecifics can be possible preadaptations in the native range for the later formation of invasive supercolonies. Alternatively, selection for increased acceptance may have taken place as lineage selection among the large number of isolated colonies in the introduced area $[8,54]$, with the likely benefit of having fewer false rejections of colony members in a changed ecological setting where different lineages will rarely compete directly $[55,56]$. One could question whether low levels of intraspecific aggression would provide species like the pharaoh ant with a competitive edge relative to other ant species as it seems likely that they do not necessarily face very intense interspecific competition in their introduced range. This is because they primarily possibly exclusively - occupy habitats that are characterized by human disturbance and therefore contain few important native competitors. Studying the species' distribution patterns on a more local scale may provide useful knowledge to evaluate which selective pressures they are exposed to, and whether low levels of intraspecific aggression potentially enabling the merger of introduced colonies may be advantageous. As successful ant invaders appear well adapted to survival in disturbed environments, the role of disturbance in ant invasions $[57,58]$ as well as in the evolution of unicoloniality $[59,60]$ is currently debated.

Absence of detectable aggression or intraspecific discrimination behaviour as measured in tests such as those applied in this study does not necessarily imply that the ants are not able to tell nestmates from non-nestmates, only that they do not react on perceived differences by exhibiting aggression [see also e.g. [53,60]]. The exact mechanism of the low level of aggression among pharaoh ants is not clear from the present study, and may therefore not reflect a lack of information, but rather an impairment in the perception of variation, a modified acceptance threshold in the colonies tested $[9,61]$, or a lack of response to perceived cues [53]. Although we cannot rule out that other substances, such as glandular secretions, may affect nestmate discrimination in pharaoh ants, the possibility that a neurological perception mechanism to ignore kinship information may have been convergently selected in invasive ants could provide an exciting area for further study.

\section{Conclusions}

We found that the investigated colonies of pharaoh ants were very highly genetically differentiated, but did not exhibit correspondingly high levels of intraspecific aggression or divergence in cuticular hydrocarbon profiles. Uniform rearing in the laboratory appeared to increase the observed level of aggression, which, if supported by additional studies, could be seen as indirect evidence for genetically based nestmate discrimination behaviour that is otherwise not expressed in more diverse environments.

No colonies stood out in terms of genetic or chemical composition, and it is therefore not possible to draw any conclusions regarding the geographical origin of the species. Further research is needed to elucidate the population genetics of the species on a finer geographical scale as well as the role of low levels of aggression towards conspecifics in the species' invasive abilities. As pharaoh ants can be kept in the laboratory and colonies crossed, it lends much promise for further investigations on these questions.

\section{Additional material}

\section{Additional file 1 Ward trees based on hierarchical cluster analyses of CHC data (a) Monomorium pharaonis and (b) M. pharaonis and $M$. destructor. ID codes for M. pharaonis are like those given in Table 1, and the M. destructor samples have been added as Md1, Md2, and Md3. (a) was con- structed in JMP.IN 5.1 based on Euclidian distance measures obtained from 18 identified cuticular hydrocarbons in M. pharaonis (see Methods for fur- ther details). The colours have been randomly assigned to the different branches. (b) was constructed in JMP 8.0 based on simple presence- absence data of the 26 cuticular hydrocarbons found in M. pharaonis and $M$. destructor combined; the $M$. destructor branches have been marked purple. \\ Additional file 2 Estimates of pairwise genetic distances $\left(F_{\mathrm{ST}}\right)$ between sampled colonies of Monomorium pharaonis based on four microsatellite loci analysed and calculated in FSTAT (Table 2).}

\section{Competing interests}

The authors declare that they have no competing interests.

\section{Authors' contributions}

AMS collected the ants and conducted the field work, carried out the behavioural assays and genetic lab work and analyses, participated in the chemical analyses and the design of the study and drafted the manuscript. PdE participated in the chemical analyses. JSP participated in the design of the study. All authors revised the draft manuscript and approved the final manuscript.

\section{Acknowledgements}

We thank Cedric Collingwood for help in species identification, David Nash and Luke Holman for assistance in analysing cuticular hydrocarbon data, Pia Gertsch, Daniel Kronauer, and Sylvia Mathiasen for help with developing primers for the microsatellite loci, Andreas Kelager for help with the BAPS analyses, and Jérôme Goudet, Pekka Pamilo, and Hans Siegismund for discussions on the genetic data. Diane Allard, Ehab Abouheif, Boris Baer, Howard Bell, Lisbeth Børgesen, the Cobblah-group, Tina Frisch, Aleksandra Gliniewicz, Chow-Yang Lee, Say-Piau Lim, Yeo Kolo, Alexander Mikheyev, David Oi, Fabien Ravery, Tsong Hong Su, Brian Taylor and Kazuki Tsuji kindly provided ant samples. Luke Holman, Tim Linksvayer, Nathan Sanders, and two anonymous referees gave valuable comments on previous versions of this manuscript. This study was supported by the Clément Foundation (AMS), CODICES Marie Curie Excellence Grant, contract number MEXT-CT-2004-014202 (PdE), the Danish Natural Sci- 
ence Research Council (JSP) and the Danish National Research Foundation (PdE, JSP). The experiments performed comply with Danish law.

\section{Author Details}

${ }^{1}$ Centre for Social Evolution, Department of Biology, University of Copenhagen, Universitetsparken 15, DK-2100 Copenhagen, Denmark and LLaboratoire d'Ethologie Expérimentale et Comparée (LEEC) University of Paris 13, 99 av. J.B. Clément, F-93430 Villetaneuse, France

Received: 26 April 2010 Accepted: 30 June 2010

Published: 30 June 2010

\section{References}

1. Wilson EO: The Insect Societies Cambridge, Massachusetts: Harvard University Press; 1971.

2. Passera L: Characteristics of tramp species. In Exotic Ants, Biology, Impact, and Control of Introduced Species Edited by: Williams DF. Boulder Colorado: Westview Press; 1994:23-43. (Breed MD (series Editor): Westview Studies in Insect Biology

3. Holway DA, Lach L, Suarez AV, Tsutsui ND, Case TJ: The causes and consequences of ant invasions. Annu Rev Ecol Syst 2002, 33:181-233.

4. Giraud T, Pedersen JS, Keller L: Evolution of supercolonies: The Argentine ants of southern Europe. Proc Natl Acad Sci USA 2002, 99:6075-6079

5. Suarez AV, Holway DA, Tsutsui ND: Genetics and behavior of a colonizing species: The invasive argentine ant. Am Nat 2008, 172:S72-S84.

6. Tsutsui ND, Suarez AV: The colony structure and population biology of invasive ants. Conserv Biol 2003, 17:48-58.

7. Tsutsui ND, Suarez AV, Holway DA, Case TJ: Reduced genetic variation and the success of an invasive species. Proc Natl Acad Sci USA 2000, 97:5948-5953.

8. Helantera H, Strassmann JE, Carrillo J, Queller DC: Unicolonial ants: where do they come from, what are they and where are they going? Trends Ecol Evol 2009, 24:341-349.

9. Starks PT: Selection for uniformity: xenophobia and invasion success. Trends Ecol Evol 2003, 18:159-162.

10. Jackson DE: Social Evolution: Pathways to Ant Unicoloniality. Curr Biol 2007, 17:R1063-R1064.

11. Cremer S, Ugelvig LV, Drijfhout FP, Schlick-Steiner BC, Steiner FM, Seifert B, Hughes DP, Schulz A, Petersen KS, Konrad H, et al: The Evolution of Invasiveness in Garden Ants. PLOS ONE 2008, 3:e3838.

12. Lenoir A, Fresneau D, Errard C, Hefetz A: Individuality and colonial identity in ants: the emergence of the social representation concept. In Information processing in social insects 1st edition. Edited by: Detrain C, Deneubourg JL, Pasteels JM. Basel: Birkhäuser; 1999:219-237.

13. d'Ettorre P, Lenoir A: Nestmate Recognition. In Ant Ecology Edited by: Lach L, Parr CL, Abbott KL. New York: Oxford University Press; 2010:197-209

14. Vander Meer RK, Breed MD, Winston ML, Espilie KE, Eds: Pheromone Communication in Social Insects: Ants, Wasps, Bees, and Termites. Boulder Colorado: Westview Press; 1998.

15. Lahav S, Soroker V, Hefetz A, Vander Meer RK: Direct behavioral evidence for hydrocarbons as ant recognition discriminators. Naturwissenschaften 1999, 86:246-249.

16. Liang D, Silverman J: "You are what you eat": Diet modifies cuticular hydrocarbons and nestmate recognition in the Argentine ant, Linepithema humile. Naturwissenschaften 2000, 87:412-416.

17. Guerrieri FJ, Nehring V, Jørgensen CG, Nielsen J, Galizia CG, d'Ettorre P: Ants recognize foes and not friends. Proc R Soc B:Biol Sci 2009, 276:2461-2468

18. Jutsum AR, Saunders TS, Cherrett JM: Intraspecific aggression in the leafcutting ant Acromyrmex octospinosus. Anim Behav 1979, 27:839-844.

19. Buczkowski G, Silverman J: Geographical variation in Argentine ant aggression behaviour mediated by environmentally derived nestmate recognition cues. Anim Behav 2006, 71:327-335.

20. Dalecky A, Renucci M, Tirard A, Debout G, Roux M, Kjellberg F, Provost E: Changes in composition of cuticular biochemicals of the facultatively polygynous ant Petalomyrmex phylax during range expansion in Cameroon with respect to social, spatial and genetic variation. Mol Ecol 2007, 16:3778-3791.

21. Berndt KP, Eichler W: Die Pharaoameise, Monomorium pharaonis (L.) (Hym., Myrmicidae). Mitt Zool Mus Berl 1987, 63:3-186.
22. Peacock AD, Sudd JH, Baxter AT: Studies in Pharaoh's ant, Monomorium pharaonis (L.). 11. Colony foundation. Entomol Mon Mag 1955, 91:125-129.

23. Edwards JP: The Biology, Economic Importance, and Control of the Pharaoh's Ant. In Economic Impact and Control of Social Insects Edited by: Bradleigh Vinson S. New York: Praeger Publishers; 1986:257-271.

24. Hölldobler B, Wilson EO: The number of queens: an important trait in ant evolution. Naturwissenschaften 1977, 64:8-15.

25. Petersen-Braun MD: Intraspecific aggression in pharaoh ant PetersenBraun MD: Monomorium pharaonis L (Hymenoptera, Formicidae). Insect Soc 1982, 29:25-33.

26. Taylor B: The Ants of (sub-Saharan) Africa. [http://antbase.org/ants/ africa//. Ants of Africa

27. Wetterer JK: Worldwide spread of the destroyer ant, Monomorium destructor (Hymenoptera: Formicidae). Myrmecol News 2009, 12:97-108.

28. Petersen-Braun MD: Untersuchungen zur Socialen Organisation der Pharaoameise Monomorium pharaonis (L.) (Hymenoptera, Formicidae). In PhD Thesis Rheinischen Friedrich-Wilhelms-Universität, Hohen Mathematish-Naturwissenschaftlichen Fakultät; 1973.

29. Goudet J: FSTAT, a program to estimate and test gene diversities and fixation indices. 2002. 2.9.3.2

30. Hedrick PW: A Standardized Genetic Differentiation Measure. Evolution 2005, 59:1633-1638.

31. Jost L: GST and its relatives do not measure differentiation. Mol Ecol 2008, 17:4015-4026

32. Heller R, Siegismund HR: Relationship between three measures of genetic differentiation GST, DEST and GST: how wrong have we been? Mol Ecol 2009, 18:2080-2083

33. Garza JC, Williamson EG: Detection of reduction in population size using data from microsatellite loci. Mol Ecol 2001, 10:305-318.

34. Corander J, Marttinen P, Siren J, Tang J: Enhanced Bayesian modelling in BAPS software for learning genetic structures of populations. $B M C$ Bioinformatics 2008, 9:539.

35. Pedersen JS, Krieger MJB, Vogel V, Giraud T, Keller L: Native supercolonies of unrelated individuals in the invasive Argentine ant. Evolution 2006 60:782-791

36. Vogel V, Pedersen JS, Giraud T, Krieger MJB, Keller L: The worldwide expansion of the Argentine ant. Diversity Distrib 2010, 16:170-186.

37. Chao A: Nonparametric estimation of the number of classes in a population. Scand J Stat 1984, 11:265-270

38. Chao A, Shen T-J: Program SPADE (Species Prediction And Diversity Estimation). 2003.

39. Goudet J: PCA-GEN, a program to perform Principal Component Analysis (PCA) on gene frequency data. 2000. 1.3.1

40. Aitchison $\mathrm{J}$ : The statistical analysis of compositional data. London: Chapman and Hall; 1986.

41. Ugelvig LV, Drijfhout FP, Kronauer DJC, Boomsma JJ, Pedersen JS, Cremer $S$ : The introduction history of invasive garden ants in Europe: Integrating genetic chemical and behavioural approaches. BMC Biol 2008, 6:14.

42. Errard C, Delabie J, Jourdan H, Hefetz A: Intercontinental chemical variation in the invasive ant Wasmannia auropunctata (Roger) (Hymenoptera Formicidae): a key to the invasive success of a tramp species. Naturwissenschaften 2005, 92:319-323.

43. Brandt M, Van Wilgenburg E, Tsutsui ND: Global-scale analyses of chemical ecology and population genetics in the invasive Argentine ant. Mol Ecol 2009, 18:997-1005

44. Dani FR, Jones GR, Destri S, Spencer SH, Turillazzi S: Deciphering the recognition signature within the cuticular chemical profile of paper wasps. Anim Behav 2001, 62:165-171.

45. Akino T, Yamamura K, Wakamura S, Yamaoka R: Direct behavioral evidence for hydrocarbons as nestmate recognition cues in Formica japonica (Hymenoptera: Formicidae). Appl Entomol Zool 2004, 39:381-387

46. Greene MJ, Gordon DM: Structural complexity of chemical recognition cues affects the perception of group membership in the ants Linephithema humile and Aphaenogaster cockerelli. J Exp Biol 2007, 210:897-905.

47. Brandt M, van Wilgenburg E, Sulc R, Shea K, Tsutsui N: The scent of supercolonies: the discovery, synthesis and behavioural verification of ant colony recognition cues. BMC Biol 2009, 7:71. 
48. Suarez AV, Holway DA, Liang DS, Tsutsui ND, Case TJ: Spatiotemporal patterns of intraspecific aggression in the invasive Argentine ant. Anim Behav 2002, 64:697-708.

49. Liang D, Blomquist GJ, Silverman J: Hydrocarbon-released nestmate aggression in the Argentine ant, Linepithema humile, following encounters with insect prey. Comp Biochem Physiol B Biochem Mol Biol 2001, 129:871-882.

50. Carlin NF, Holldobler B: The kin recognition system of carpenter ants (Camponotus Spp) .1. Hierarchical cues in small colonies. Behav Ecol Sociobiol 1986, 19:123-134.

51. Caldera EJ, Holway DA: Evidence that queens do not influence nestmate recognition in Argentine ants. Insect Soc 2004, 51:109-112.

52. Vander Meer RK, Alonso LE: Queen primer pheromone affects conspecific fire ant (Solenopsis invicta) aggression. Behav Ecol Sociobiol 2002, 51:122-130.

53. Steiner FM, Schlick-Steiner BC, Moder K, Stauffer C, Arthofer W, Buschinger A, Espadaler X, Christian E, Einfinger K, Lorbeer E, et al:: Abandoning aggression but maintaining self-nonself discrimination as a first stage in ant supercolony formation. Curr Biol 2007, 17:1903-1907.

54. Nunney L: Lineage selection: natural selection for long-term benefit. In Levels of Selection in Evolution Edited by: Keller L. New Jersey: Princeton University Press; 1999:238-252

55. Crozier RH: Genetic Clonal Recognition Abilities in Marine Invertebrates Must be Maintained by Selection for Something Else. Evolution 1986, 40:1100-1101.

56. Ratnieks FLW: The Evolution of Genetic Odor-Cue Diversity in Social Hymenoptera. Am Nat 1991, 137:202-226.

57. King JR, Tschinkel WR: Experimental evidence that human impacts drive fire ant invasions and ecological change. Proc Natl Acad Sci USA 2008, 105:20339-20343

58. King JR, Tschinkel WR, Ross KG: A case study of human exacerbation of the invasive species problem: transport and establishment of polygyne fire ants in Tallahassee, Florida, USA. Biol Invasions 2009, 11:373-377.

59. Nakamaru M, Beppu Y, Tsuji K: Does disturbance favor dispersal? An analysis of ant migration using the colony-based lattice model. J Theor Biol 2007, 248:288-300.

60. Tsuji K: What brings peace to the world of ants (Hymenoptera: Formicidae)? Myrmecol News 2010, 13:130-132.

61. Reeve HK: The Evolution of Conspecific Acceptance Thresholds. Am Nat 1989, 133:407-435.

doi: $10.1186 / 1742-9994-7-20$

Cite this article as: Schmidt et al., Low levels of nestmate discrimination despite high genetic differentiation in the invasive pharaoh ant Frontiers in Zoology 2010, 7:20

Submit your next manuscript to BioMed Centra and take full advantage of:

- Convenient online submission

- Thorough peer review

- No space constraints or color figure charges

- Immediate publication on acceptance

- Inclusion in PubMed, CAS, Scopus and Google Scholar

- Research which is freely available for redistribution

Submit your manuscript at www.biomedcentral.com/submit
C Biomed Central 